Japan. J. Med. Sci. Biol., 24, 271-279, 1971

\title{
NEPHROTOXIC EFFECT OF MSG (MONOSODIUM GLUTAMATE) IN THE CHICKEN
}

\author{
TSUTOMU SHIMIZU, RITSUKo HIROHATA, YASUKo NOMURA, \\ KAGEAKI AIBARA AND KOMEI MIYAKI \\ Department of Food Research, National Institute of Health, \\ Shinagawa-ku, Tokyo 141, Japan
}

(Received: July 20th, 1971)

\begin{abstract}
SUMMARY : In order to prove sodium toxicity of MSG, baby chicks known to be the most susceptible one to sodium chloride were chosen as the experimental animal. Almost isotonic solution of MSG, $\mathrm{NaCl}$ or monopotassium glutamate was given ad libitum as the sole source of drinking water. Two-day old chickens given MSG died of gout within a few days and showed higher mortality and lesions severer than those given physiological saline, while none died nor was weakened among those receiving monopotassium glutamate. Very rapid development of kidney lesions and a large amount of urate deposits were the two main features resulting from MSG ingestion, and primary histological changes were tubular degeneration and tophi obstruction in collecting ducts. Even at half concentration, MSG ingestion caused lobar atrophy in the kidney and some died of gout. Besicies sodium toxicity, glutamate counterpart is suspected of contributing to uric acid synthesis.
\end{abstract}

\section{INTRODUCTION}

In recent years MSG has been noticed as the causative agent of hypothalamic and retinal lesion in new born animals (Olney, $1969 \mathrm{a}, \mathrm{b}$ ). Amino acid portion of MSG has been considered as the main causative agent in explaining the mechanism of these lesions with a relatively little attention paid to the sodium part (Olney, 1970; Freedman and Potts, 1962). However, it is an established fact in veterinary science that various sodium salts cause nervous symptoms in animals and especially in poultry they are nephrotoxic (Smith and Jones, 1966). Further, it has recently been found that rats and hamsters administered MSG and $\mathrm{NaCl}$ by gastric intubation develop marked nervous symptoms and $\mathrm{LD}_{50}$ values in both species turned out to be quite parallel to the concentration of sodium ions (Shimizu et al., 1971). To observe sodium toxicity of MSG we chose the chicken as the most susceptible experimental animal to $\mathrm{NaCl}$ with its characteristic development of nephrosclerosis (Selye, 1942). A 2.6\% MSG solution given to baby chickens as the exclusive source of drinking water showed higher toxicity than $0.9 \%$ saline which had been reported to be fatal in a few days (Doll et al., 1946). In the present paper we report macroscopic and microscopic findings of the chickens given MSG, $\mathrm{NaCl}$ or monopotassium glutamate added to the drinking water.

清水 孜・広鰔 律子・野村 泰子・栗飯原景昭・宮木 高明（国立予防衛生研究所 食品衛生部） 


\section{MATERIALS AND METHODS}

Solutions of MSG and $\mathrm{NaCl}$ were prepared to contain the same amount of sodium ions, and the solution of equivalent monopotassium glutamate (abbreviated to KG) was adopted in order to eliminate sodium toxicity. Osmotic pressure of solutions of $2.6 \% \mathrm{MSG}, 0.9 \% \mathrm{NaCl}$ and $2.8 \% \mathrm{KG}$ were 243,280 and $258 \mathrm{~m} 0 \mathrm{sm}$, respectively.

Two-day old hybrid chickens were divided into five groups and started to receive each solution as drinking water (ad libitum); test group A $2.6 \% \mathrm{MSG}$, test group B $1.3 \% \mathrm{MSG}$, test group C $0.9 \% \mathrm{NaCl}$, test group D $2.8 \% \mathrm{KG}$, and control group distilled water; all these groups were fed with commercial chick food containing $0.1-$ $0.3 \%$ of sodium chloride. Observation continued for 4 weeks.

On post mortem examinations of dead and sacrificed birds, joints were carefully observed. All organs were fixed in Bouin's fluid and $10 \%$ neutral buffered formalin, embedded in paraffin, and sections were cut at $5 \mu$ and stained with haematoxylin and eosin.

\section{RESULTS}

Mortality and weight gains are shown in Table 1 and Fig. 1, respectively.

Most of the chickens given $2.6 \%$ MSG (test group A) died within 3 days. They had neither eaten nor drunk for half to a full day before death, stood still with their eyes closed, then succumbed on the floor chirping weakly, and of ten lost balance due to stiff joints of the legs. At necropsy marked deposits of white substance were recognized on the pericardium, air sacs, serous surface of internal organs, fascial mem-

Table 1. Mortality in chickens given various salts in drinking water (ad libitum)

\begin{tabular}{|c|c|c|c|c|c|c|c|c|c|c|c|c|c|c|c|c|}
\hline \multirow{2}{*}{ Group } & \multirow{2}{*}{ Solution } & \multicolumn{14}{|c|}{ Post hatching date } & \multirow{2}{*}{$\begin{array}{l}\text { Death } \\
\text { rate }\end{array}$} \\
\hline & & 1 & 2 & 3 & 4 & 5 & 6 & 7 & 8 & 9 & 10 & 11 & 12 & 13 & $14-30$ & \\
\hline A & $\begin{array}{l}\text { MSG } 2.6 \% \\
\text { o.p. } 243 \mathrm{~m} 0 \mathrm{sm}\end{array}$ & & & 0 & 6 & 16 & 3 & 5 & & & & & & & & $30 / 30$ \\
\hline B & MSG $1.3 \%$ & & & 0 & 0 & 1 & 0 & 0 & 0 & 0 & 0 & 1 & 0 & 0 & 0 & $2 / 30$ \\
\hline C & $\begin{array}{l}\mathrm{NaCl} 0.9 \% \\
\quad \text { o.p. } 280 \mathrm{~m} 0 \mathrm{sm}\end{array}$ & & & 0 & 0 & 2 & 0 & 1 & 1 & 2 & 1 & 0 & 0 & 1 & 0 & $8 / 20$ \\
\hline $\mathrm{D}$ & $\begin{array}{l}\mathrm{KG} 2.8 \% \\
\text { o.p. } 258 \mathrm{~m} 0 \mathrm{sm}\end{array}$ & & & 0 & 0 & 0 & 0 & 0 & 0 & 0 & 0 & 0 & 0 & 0 & 0 & $0 / 19$ \\
\hline \multicolumn{2}{|c|}{$\begin{array}{l}\text { Control } \\
\text { (distilled water) }\end{array}$} & & & 0 & 0 & 0 & 0 & 0 & 0 & 0 & 0 & 0 & 0 & 0 & 0 & $0 / 31$ \\
\hline
\end{tabular}

branes of muscles and in joints and kidneys (Figs. 2, 3, 4). In severe cases it covered all the surface of the abdominal wall both inside and outside accompanying visceral adhesion and deposited in the spleen and gall bladder (Figs. 5, 6). In all cases the kidneys were pale, swollen and diffusely studded with minute white substance and chalky substance of ten plugged the dilated ureters (Fig. 4).

The tophaceous substance was Murexid reaction positive, showed needle shaped birefringent crystals under polarized microscopy (Fig. 10), and disappeared by the action of uricase. It also revealed maximum ultraviolet absorption at $292 \mathrm{~m} \mu, \mathrm{pH} 9.4$. 


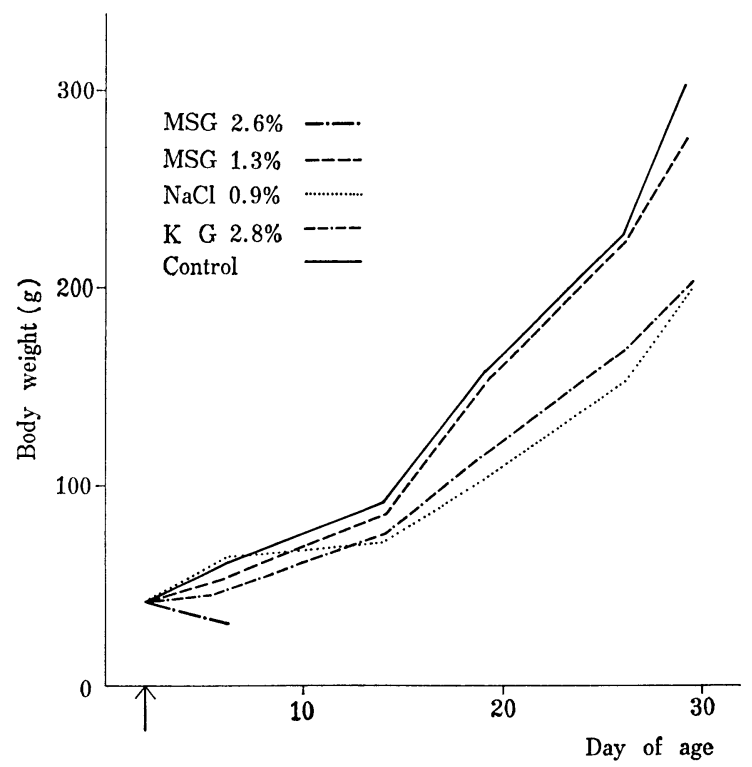

Fig. 1. Weight gains of chickens receiving various salts in drinking water.

On the other hand, sodium was detected in the tophi, suggesting the presence of sodium urate.

In test group B (which received 1.3\% MSG in drinking water), only 2 chickens died of gout on the 3rd (visceral type) and the 9th (articular type) days of experiment. Clinical features of the two were identical to those of group A. All other chickens showed apparently normal growth, but when they were sacrificed at 35 day of age, 10 of 28 birds revealed various degree of renal atrophy in some lobes of the kidney (lobar atrophy), associated with compensatory hypertrophy (Fig. 7).

Soon after the start of the experiment in both test groups $\mathrm{C}$ and $\mathrm{D}$ the feces became very watery. In a few days diarrhea became milder in the chickens receiving $\mathrm{KG}$ but it persisted or was rather aggravated for more than a week in those given $\mathrm{NaCl}$. However, the chickens did not lose their appetite and especially those of group $\mathrm{C}$ ate and drank voraciously.

Eight of the 20 chickens of group $\mathrm{C}$ died by the 11 th day of experiment. During the 3 rd to the 7 th days of the experiment they revealed subcutaneous oedema attributable to renal failure and subsequently died. Pericardial oedema and fluid in body cavity were common findings (Fig. 8). The affected kidneys were pale in colour, of ten hardened and sometimes swollen but no partial deformity was observed, nor the slightest deposition of tophi (Fig. 9). The average weight of the surviving 12 birds was light. They were dirty and looked miserable.

All the chickens having received KG showed no sign of weakness and survived till the end of the experiment. Although they were smaller than normal in size, no macroscopic or microscopic change was found in their internal organs.

No abnormal finding was observed in the control group.

On histological study, obstruction of collecting ducts with urate deposits was 

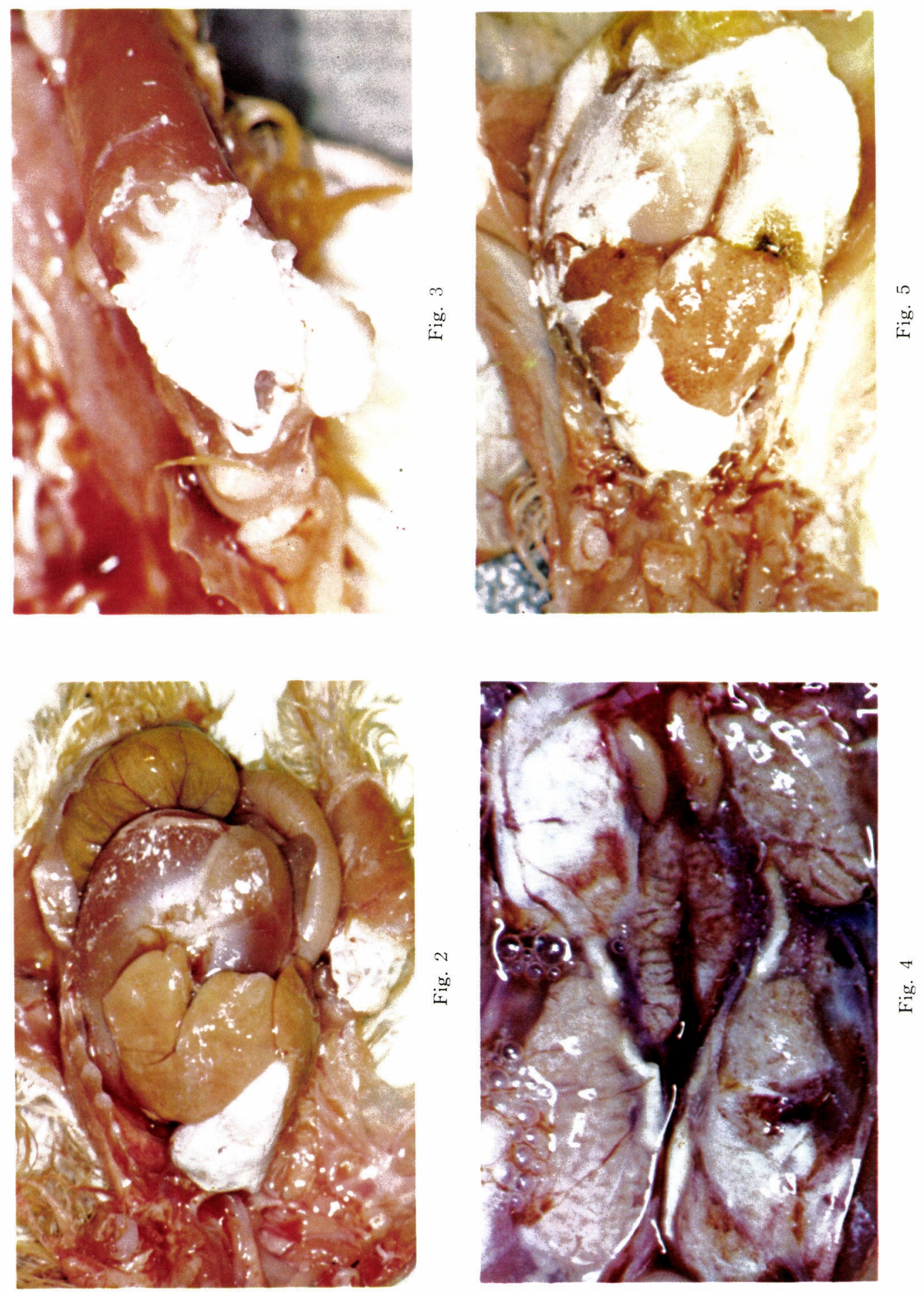

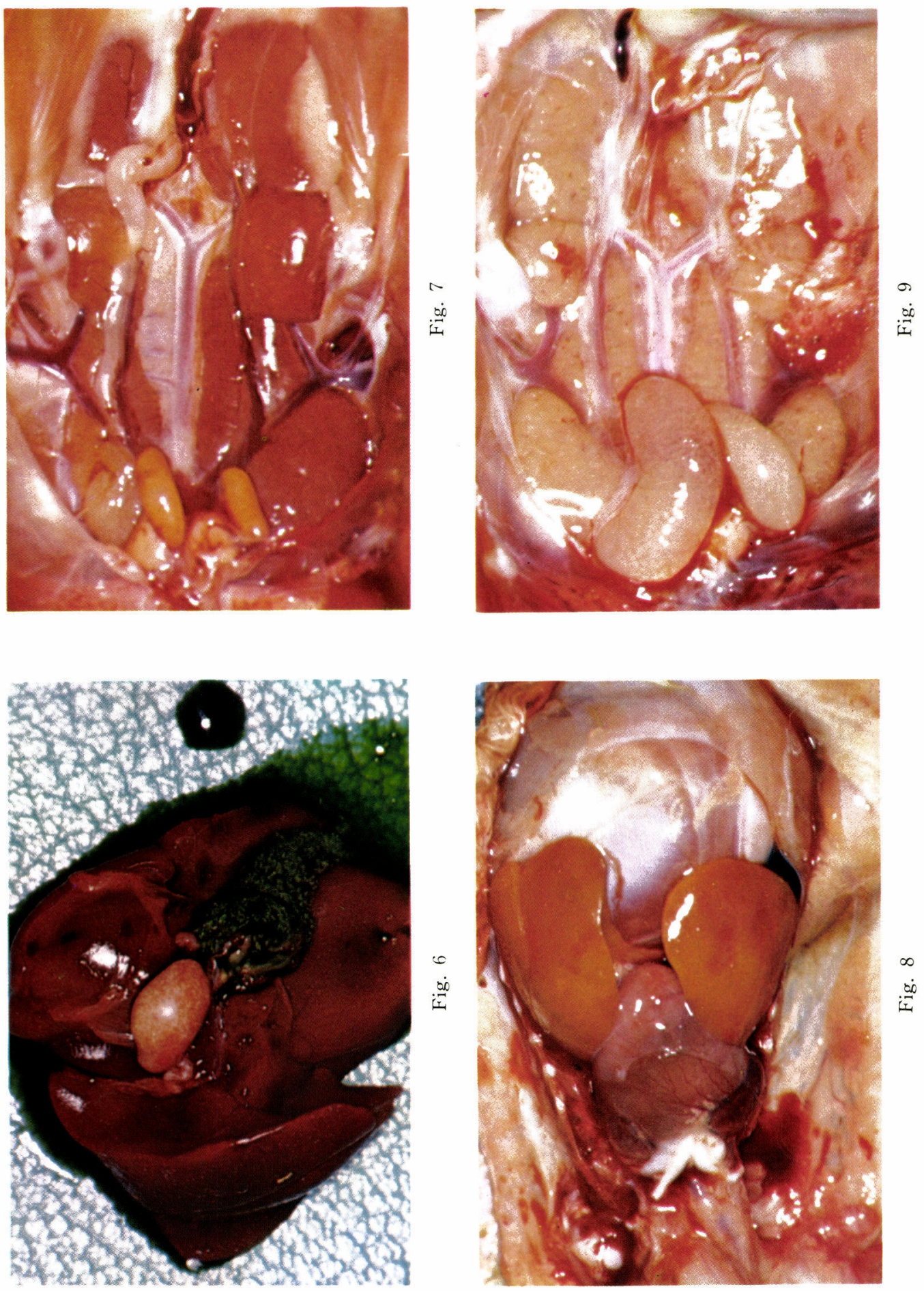

$\infty$
0
$\dot{1}$ 

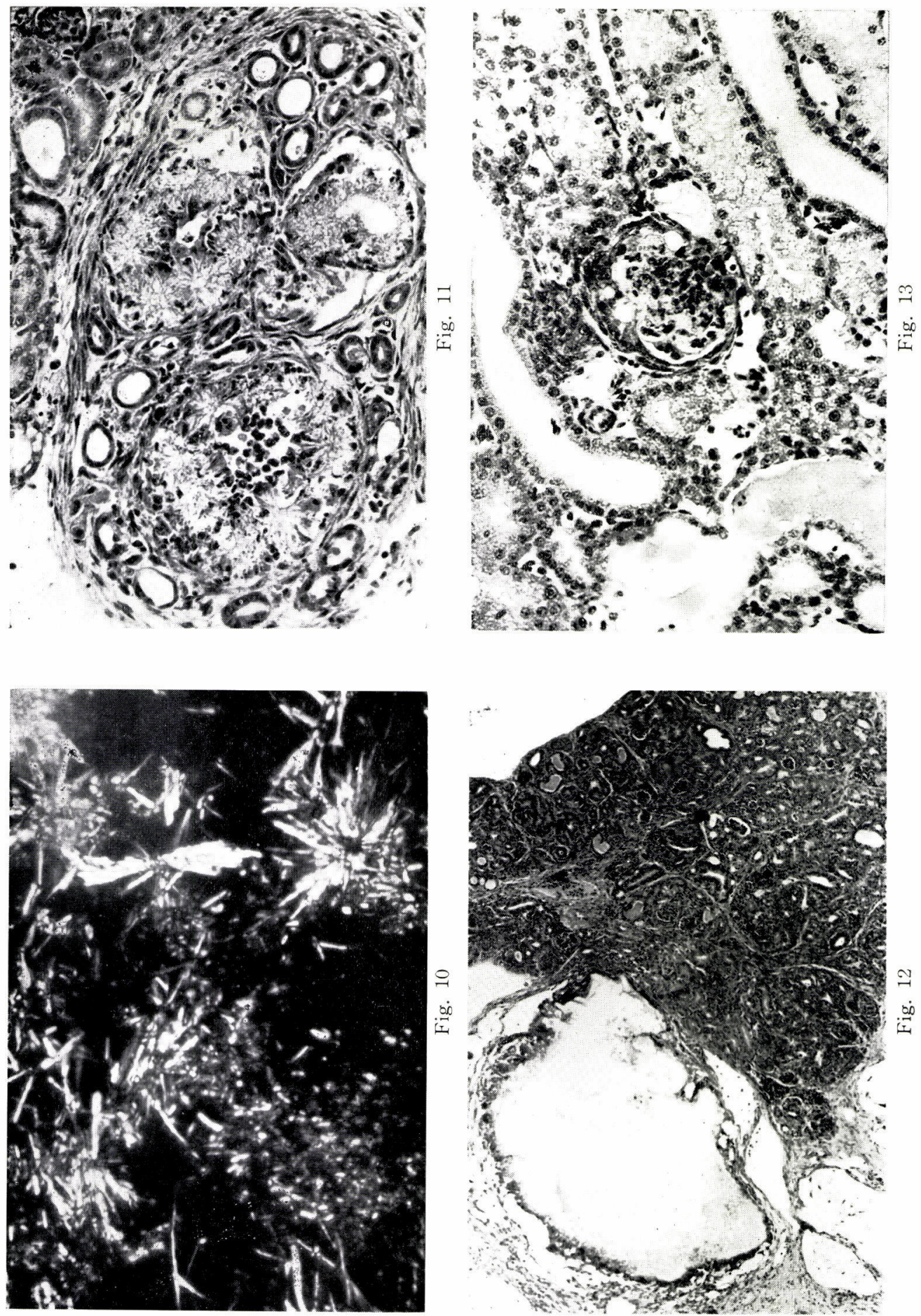


\section{EXPLANATION OF FiguRES}

Fig. 2. Group A. Heavy urate deposits on the pericardium and left knee joints (lower middle); lower degree on the serous surface of the gizzard.

Fig. 3. Group A. Heavy urate deposits on the knee joint.

Fig. 4. Group A. Swollen pale kidneys studded with minute white spots. The serous surface of the right cranial lobe is encrusted with urate. Dilated ureters are plugged with chalky substance.

Fig. 5. Group A. Severe urate deposits and subsequent visceral adhesion.

Fig. 6. Group A. Urate deposits in the spleen and gall bladder.

Fig. 7. Group B. Atrophy of left cranial lobe and compensatory hypertrophy of right lobes.

Fig. 8. Group C. Marked pericardial oedema.

Fig. 9. Group C. Pale, swollen and a little hardened kidneys and oedematous swelling testes.

Fig. 10. Needle shaped crystals under polarized microscopy. $\times 400$

Fig. 11. Group A. Intraductal tophi accumulation surrounded by heterophils and giant cells; thin and thick limbs are intact. $\times 100$

Fig. 12. Group B. A large tophus surrounded by giant cells (left) and atrophic kidney tissue (right). $\times 10$

Fig. 13. Group C. Epithelial crescent in a renal corpuscle and vacuolar degeneration of proximal tubules. $\times 100$ 
prominent in gouty kidneys of groups A and B. Being surrounded by heterophils or giant cells, intraductal tophi seemed to stop the urinary flow and ruinate associated tubules (Fig. 11). Colloid retention or tubular dilatation was not uncommon. Oedematous and fibrous tendency was observed in the interstitial tissue. The glomerular lesion known to occur in $\mathrm{NaCl}$ poisoning was not encountered. No particular lesion was recognized in the brain or retina. Only tophaceous deposits surrounded by giant cells were sometimes seen in other organs. The atrophic lobe of the kidney in group $\mathrm{B}$ proved to be once ruinated shrunken kidney tissue (Fig. 12). Poisoned kidney of group $\mathrm{C}$ revealed nephrosclerosis and diffuse vacuolar degeneration of proximal tubules (Fig. 13), while collecting ducts remained intact.

\section{DISCUSSION}

Many sodium salts are reported to be goutgenic to the fowl (Bokiri, 1966). In the present experiment a strong nephrotoxic effect of MSG in baby chickens was demonstrated as intraductal tophi accumulation, while $\mathrm{NaCl}$ mainly affected the upper part of nephron. The gouty lesion caused by MSG ingestion is distinguishable for its rapidity and accuracy. Elimination of sodium toxicity by the use of monopotassium glutamate was successful, but marked retardation of weight gain, probably attributable to initial diarrhea, occurred.

The causes of rapid obstruction in collecting ducts are inferred as follows: Uric acid is synthesized in too large amount to drain. (2) Reabsorption of water in renal tubules is activated. It is well known that glutamine works as a precursor in purine synthesis. According to Katsunuma et al. (1970), in birds the presence of glutamate strongly inhibited glutaminase and the feedback inhibition of PRPP-amidotransferase by AMP, IMP or GMP was less than that in mammals. Suspicion is strengthened that the acid part of MSG may contribute to the uric acid overproduction. In fact, most of the gouty chickens revealed heavy urate deposition on visceral surface and in joints at the same time, which was rare in both spontaneous cases (Siller, 1959) and artificially produced gout (Bokiri, 1965, 1966).

As chickens excrete very concentrated urine, water reabsorption in renal tubules must be of high efficiency. Immaturity of tubular membrane may conduce to higher permeability. $\mathrm{ADH}$ (anti-diuretic hormone) may participate in its mechanism to activate facultative water reabsorption in collecting ducts and distal tubules. Such speculations need further inquiry into urine.

Sodium not collaborating with chloride may bring up a little different effects to the kidney. Tubular degeneration caused by MSG ingestion was focal, whereas diffuse in $\mathrm{NaCl}$ intoxication, and glomerular lesion typical of the latter was absent in the former. Investigation of the blood may be necessary to clarify hypernatremia and hyperuricemia.

Membranous transportation of $\mathrm{Na}^{+}$and glutamate is assumed to require a common carrier (Curran et al., 1967), and owing to the renal portal system, the kidney of the bird may receive direct influence of MSG in the gut. So, the coodination of sodium and glutamic acid may be the key to clarify this phenomenon. Though avian gout is not directly connected with human gout, further study will be required on the mechanism of nephrotoxicity of MSG. 


\section{REFERENCES}

BOKIRI, J. (1965): Studies on nutritional gout in poutry II The aetiological role of A-avitaminosis in poutry gout, Acta vet. Acad. Sci. Hung., 15, 421-440.

BokIRI, J. (1966): Gout in Poultry. III. Production of gout by chemical damage to the kidneys, Acta vet. Acad. Sci. Hung., 16, 273-286.

Curran, P. F., Schultz, S. G,. Chez, R. A. ANd Fuisz, R. E. (1967): Kinetic relations of the Na-amino acid interaction at the mucosal border of intestine. J. Gen. Physiol., 50, 1261-1286.

Doll, E. R., HUll, F. E. AND INSKo W. M., JR. (1964): Toxicity of sodium chloride solution for baby chicks. Vet. Med., 41, 361-363.

FREEDMAN, J. K. AND POTTS, A. M. (1962): Repression of glutaminase I in the rat retina by administration of sodium-L-glutamate. Invest. Ophth., 1, 118-211.

Katsunuma, N., Matsuda, Y. AND Kuroda, Y. (1970): Phylogenic aspects of different regulatory mechanisms of glutamine metabolism. Advances in Enzyme Regulation, 8, $73-81$.

OLNEY, J. W. (1969a): Brain lesions, obesity and other disturbances in mice treated with monosodium glutamate. Science, 164, 719-721.

OLNEY, J. W. (1969 b): Glutamate induced retinal degeneration in neonatal mice. Electron microscopy of the acutely evolving lesion. J. Neuropath. Exp. Neurol., 28, 455-474.

OLNEY, J. W. AND OI-LAN Ho (1970): Brain damage in infant mice following oral intake of glutamate, aspartate or Cysteine. Nature, 227, 609-610.

SELYE, H. (1942): Role of sodium chloride in production of nephrosclerosis by steroids. Canad. Med. Assoc. J., 47, 190-193.

Shimizu, T., Hirohata, R., Nomura, Y. AND Aibara, K. (1971): Acute toxicity of excessive MSG ingestion in the hamster. Jikken-Dobutsu, in press, (text in Japanene).

SilleR, W. G. (1959): Avian nephritis and visceral gout. Lab. Invest., 8, 1319-1357.

Smith, H. A. AND Jones, T. C. (1966): Veterinary Pathology, 3rd ed. Lea and Febiger, Philadelphia. $1192 \mathrm{p}$. 